\title{
Effect of various number conical strip inserted in the tube on heat transfer performance
}

\author{
M. Anis Mustaghfirin ${ }^{1 *}$, Burniadi Moballa ${ }^{1}$, and Syaifullah Hamim Thohari $^{1}$ \\ ${ }^{1}$ Program Studi Teknik Perpipaan, Jurusan Teknik Permesinan Kapal, Politeknik Perkapalan Negeri \\ Surabaya, 60111 Surabaya Indonesia
}

\begin{abstract}
This work, fluid flow and heat transfer in single and multi phase flow chould be enhanced by turbulent flow in heat exchanger tube with one of heat transfer augmentation techniques. Characteristic of globular tube fitted with the multiple conical strips insert were investigated. Most of study are related with this work, they found that an addition by single conical strips insert will make nusselt number increase $5 \%$. Unfortunately, it was also increase pressure drop about $10 \%$. This work improve their work by adding amount of conical strips inserts. The modification that will become 4 variation number of conical $(\mathrm{n}=2,3,4$, and 5) with 4 kind of central angle $\left(\alpha=20^{\circ}, 30^{\circ}, 40^{\circ}\right.$, and $\left.50^{\circ}\right)$, it is shown that the best performance of conical strips insert configuration is 2 peace of strips with $20^{\circ}$ central angle. This work successfull improve Performance heat transfer value in tube about $11 \%$ compare with A. Fan et al work. Thus achieve a high overall heat trasnfer performence and it is a promising tube insert which would be widely used in heat transfer process turbulent flow.
\end{abstract}

\section{Introduction}

Heat transfer equipment in project industry, power plant, chemical fields, and engineering area become indispensable devices. Heat exchanger tubes stand in a wide variety of heat transfer equipment [1].To increase the heat transfer rate of the tube flow, numerous studies on heat transfer enhancement techniques have been carried out. Among the heat transfer enhancement techniques for tube flow, tube inserts are widely researched because of their easy of manufacture and instalation.

There have been several studies on the effect of conical strip inserts on concentric pipe objects such as Promvonge et al. [2]. Conducted research on conventional heat transfer in tubes heated by constant heat flux with passive method, some conical rings were used as turbulators attached for testing on the tube. Conical rings with variations of 3 different diameter ratios $(\mathrm{d} / \mathrm{D}=0,5 ; 0,6 ; 0,7)$. Kongkaitpaiboon, dkk [3] In this paper analyze experimentally the effects of PCR on convection heat transfer, friction factor, thermal performance. For PCR variations use 3 different pitch ratios $(P R=p / D=4,6,12)$ and three different holes $(n=4,6,8)$. Fan, et al [4] in this journal made efforts to increase heat transfer without significant pressure increase, in this journal also develop turbulent strip-shaped cone. The characteristics of heat transfer rate, durability, and overall thermo-hydraulic performance

\footnotetext{
* Corresponding author: mustaghfirin@ppns.ac.id
} 
of turbulent flow in a globular tube inserted by conical strip inserts in this journal were investigated using numerical studies. The maximum result friction factor of the modified tube increases by 10 times ( $f=0.062-0.36$ ); while the value of Nusselt number increases 5 times ( $\mathrm{Nu} 98.35$ - 400.41) of the smooth tube. Sripattanapipat, et al [5] In this journal modify previous research on conical ring (CR) into hexagonal conical rings (HCR) which will be used as turbulent flow trigger to produce vortex flow which is aimed at increasing the rate of heat transfer inside tube heat exchanger. To reduce the pressure losses the shape of the $\mathrm{V}$ $\mathrm{HCR}$ is made with the symmetrical plane of the cone, with variations of attack angle $\left(30^{\circ}\right.$, $45^{\circ}$, and $60^{\circ}$ ). Pourramezan, et al [6] In this s investigate the numerical simulation of thermohydrolic of turbulent characteristics flow within the circular tube in the presence of twisted conical inserts.

\section{Numerical model describtion}

\subsection{Geometrical model}

The geometrical model of the conical strips insert and schematic diagram of tube fitted with the multiple conical strips insert are presented in Figure 1. The conical strip is made from surface of cone. The geometric parameters of diameter tube (Dt) is 19,6 mm, the slant angle $(\theta)$ is $90^{\circ}$, the pitch of conical strips $(p)$ is $30 \mathrm{~mm}$, the lenght of conical strip (Lc) is $16 \mathrm{~mm}$, the thickness of conical strip (t) is $1 \mathrm{~mm}$. Conical strips are combine to a central rod with a diameter of $1 \mathrm{~mm}$. The full length of tube for simulation (L) is $300 \mathrm{~mm}$. To generate three dimensional tube respectively, inserts with four different numbers of conical strips at a geometry location $(n=2,3,4$, and 5) were studied in the current work. To investigated the effect of central angle on heat transfer performence and taking into estimation that the limitation of $n \times \alpha<360$, inserts with central angle $\left(\alpha=20^{\circ}, 30^{\circ}, 40^{\circ}\right.$, and $\left.50^{\circ}\right)$. Heat conduction in the conical strips and central rod is neglected. The thickness of coompact tube wall is not considered.
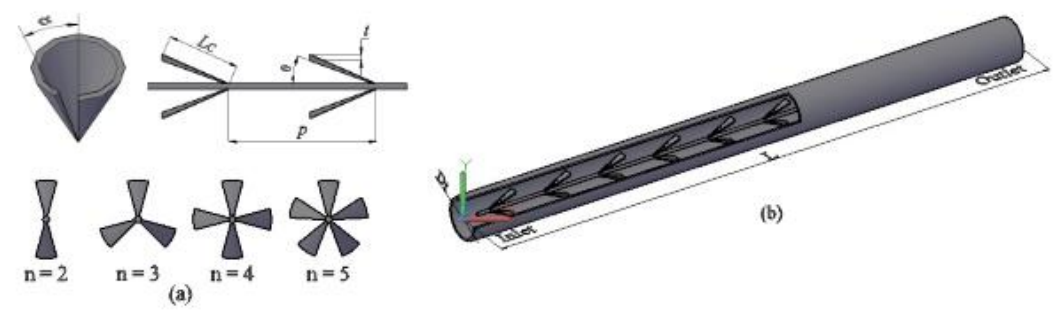

Fig. 1. (a) Model of multiple strips inserts, (b) schematic diagram of tube with conical strips inserts.

\subsection{Governing equations}

Air was chosen as the operational fluid in this work. The subsequent assumptions are made for computation model: (1) the fluid is newtonian, incompressible, isotropic, and continuous. The physical properties of the fluid are constant and are set to be: $\rho=1,18415 \mathrm{~kg} / \mathrm{m}^{3}, \mu=$ $1,85 \times 10^{-5} \mathrm{~Pa} \mathrm{~s}, C_{p}=1003,62 \mathrm{~J} / \mathrm{kg} \mathrm{K}$, and $\mathrm{q}=30,28 \mathrm{~W} / \mathrm{m}^{2}$; (2) the insert is stiff (the deformation and vibration of insert are ignored); and (3) the effects of viscous heating, thermal radiation, and gravity are not taken into consideration.

The flow field in this work is three-dimensional, turbulent, and steady. The governing equation of continuity, momentum, and energy for fluid flow are given as follows:

Continuity equation: 


$$
\frac{\partial \rho}{\partial t}+\nabla(\rho U)=0
$$

Momentum equation :

$$
\frac{\partial}{\partial x_{j}}\left(\rho u_{i} u_{j}\right)=-\frac{\partial p}{\partial x_{i}}+\frac{\partial}{\partial x_{j}}\left[\mu\left(\frac{\partial u_{i}}{\partial x_{j}}+\frac{\partial u_{j}}{\partial x_{i}}\right)-\frac{2}{3} \mu \frac{\partial u_{k}}{\partial x_{k}} \delta_{i j}\right]
$$

Energy equation :

$$
\frac{\partial}{\partial x_{j}}\left(\rho u_{j} C_{P} T-k \frac{\partial T}{\partial x_{j}}\right)=u_{j} \frac{\partial p}{\partial x_{j}}+\left[\mu\left(\frac{\partial u_{i}}{\partial x_{j}}+\frac{\partial u_{j}}{\partial x_{i}}\right)-\frac{2}{3} \mu \frac{\partial u_{k}}{\partial x_{k}} \delta_{i j}\right]
$$

All the governing equation were solved by using CFD software, which is based on the finite volume method. The AMG solver was used to obtain a solution for the coupling between pressure and velocity. The minimum convergence criterion or stopping criterion was that the residuals were less then $10^{-4}$ for continuity and momentum equations and less than $10^{-3}$ for energy equation.

\subsection{Grid generation and independence test}

Three-dimensional grid geometrical for the computational domain was generated using CFD software. The grid system used in the present numerical labor is shown in Figure 2. To simulate the boundary layer outcome accurately, a highly fine grid, was adopted in the region near the tube wall. In addition, Sectional grid refinement was applied in the region near the conical strips insert surfaces. Tetrahedral grids in meshing step were generated to capture the fluid flow in the core region.

Grid independence test was carried out for conical strips inserts with $n=2, \alpha=40^{\circ}$, and example Reynold number is 24000 . Average grid systems should same with A. Fan et al, that is 2.000.000 grids. The results indicate that grids use more than 2.milion grids calcualtion from AMG solver more beter than under 2 milion grids.
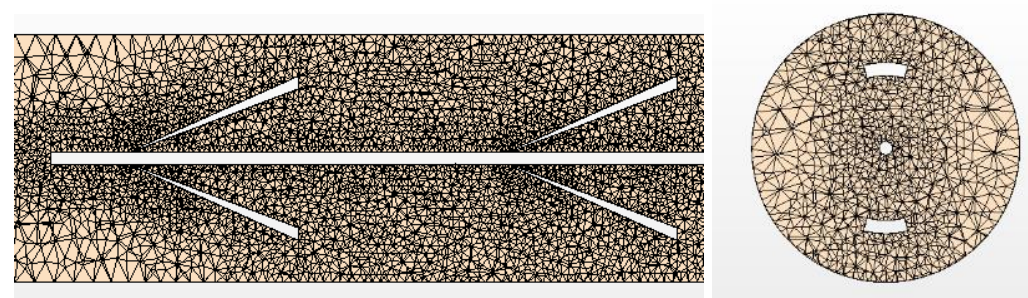

Fig. 2. Grids for the computation domain.

\subsection{Boundary condition}

On the tube wall, a constant heat flux conition was specified. In order to eliminate inlet outcome, the fully extend profiles of velocity and temperature which are defined as Figure 3 were imposed at the inlet. An outflow condition was used pressure outlet, and a no slip condition was applied on the wall and surfaces of the conical strips insert. Heat conduction and radiation of the conical strips insert were ignored in this study. 


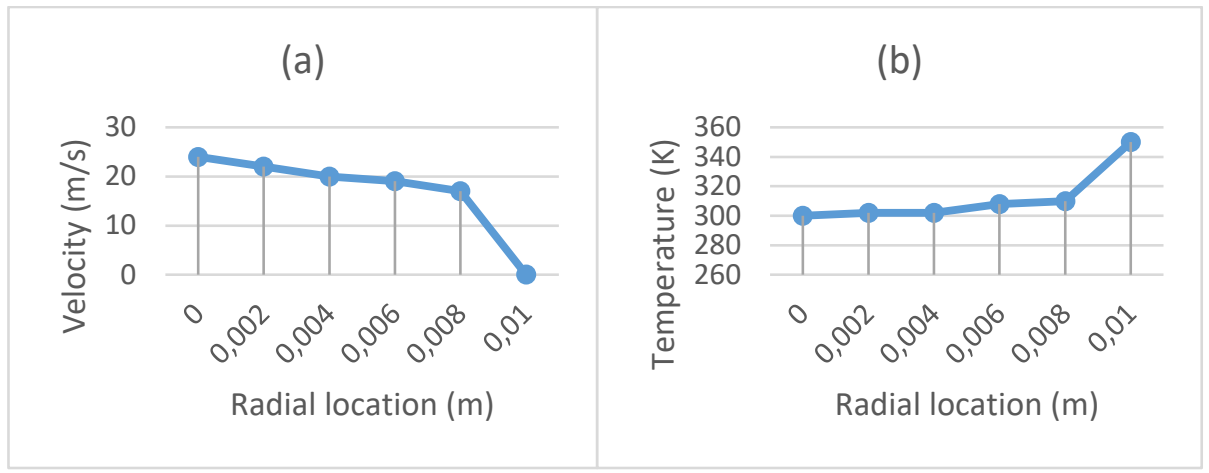

Fig. 3. Fully developed flow and temperature boundary condition applied at the tube inlet: (a) velocity, and (b) temperature.

\section{Ressult and discussions}

\subsection{Calculation of the Nusselt number, friction factor, and PEC}

On the tube wall, a constant heat flux condition wa spesified. In order to eliminate inlet effect, the fully extend profiles of velocity and temperature which are defined as Eqs. (4) and (5) were imposed at the inlet. An outflow condition was used at the outlet, and a no slip condition was applied on the wall and surfaces of the conical strips insert. Heat conduction and radiation of the conical strips insert were ignored in this study. Therefore, a heat insulation condition was used on the surfaces of conical strips insert.

Inlet velocity condition :

Inlet temperature :

$$
u=u_{c}\left(1-\frac{r^{2}}{R^{2}}\right)
$$

$$
T=T_{c}+\frac{q R}{\lambda}\left[\left(\frac{r}{R}\right)^{2}-\frac{1}{4}\left(\frac{r}{R}\right)^{4}\right],
$$

where $u_{c}$ and $T_{c}$ are the velocity and temperature at the center position of the inlet crosssection. In addition, $R$ is the inner radius of the tube, $r$ is the radial distance, and $q$ is the heat flux in the tube.

The reynolds number $(R e)$ and heat transfer coefficient $(h)$ are given as:

$$
\begin{aligned}
& R e=\frac{\rho u_{m} D}{\mu}, \\
& h=\frac{q}{T_{w}-T_{m}},
\end{aligned}
$$

where $u_{m}$ is the mean velocity of fluid in the tube, $T_{w}$ is the average temperature a long of tube wall, and $T_{m}$ is fluid bulk temperature inside the tube.

$$
T_{m}=\frac{1}{2}\left(T_{\text {in }}+T_{\text {out }}\right),
$$

where $T_{\text {in }}$ and $T_{\text {out }}$ are mass average temperature of inlet and outlet, respectively.

The Nusselt number $(\mathrm{Nu})$ and friction factor $(f)$ are defined as follows:

$$
\begin{gathered}
N u=\frac{h D}{\lambda}, \\
f=\frac{\Delta P}{\left(\frac{1}{2} \rho u_{m}^{2}\right)(L / D)},
\end{gathered}
$$

Where $\lambda$ and $\rho$ is heat conductivity coefficient and density of fluid respectively, $\Delta P$ is the pressure drop between the inlet and outlet.

The Performance Evaluation Criteria (PEC) is defined as following ways: 


$$
P E C=\frac{N u / N u_{0}}{\left(f / f_{0}\right)^{1 / 3}},
$$

Where $N u$ and $N u_{0}$ are the Nusselt numbers of the enhanced tube and smooth tube, respectively; while $f$ and $f_{0}$ are the friction factors of the enhanced tube and smooth tube, respectively. From the above formula one can see that the PEC value of an effective enhancement techniqe should be at least larger than unity. The larger the PEC value will make design more better and efficient.

\subsection{Variation of the Nusselt number, friction factor, and PEC}

Fig. 4 depict the variations of the Nusselt number versus number of strips for conical strips inserts with different central angles. It is noted that the best Nusselt number is $20^{\circ}$ central angle and 2 peace strips inserts. Contrast with nusselt number, the friction factor in Figure 5 decrease with increase central angle. Moreover, the friction factor increases with the nominal strips. Figure 6. The variation tendency of performence evaluation criteria (PEC) versus number of strips different from the Nusselt number and friction factor, the variation of PEC is not monotonically. In otherothers words, it will increses with decrease of nominal strips and small central angle. The PEC value of conical strips with 5 peace strips with $50^{\circ}$ central angle almost same with value of conical strips with 5 peace strips with $40^{\circ}$ and $30^{\circ}$ central angle.

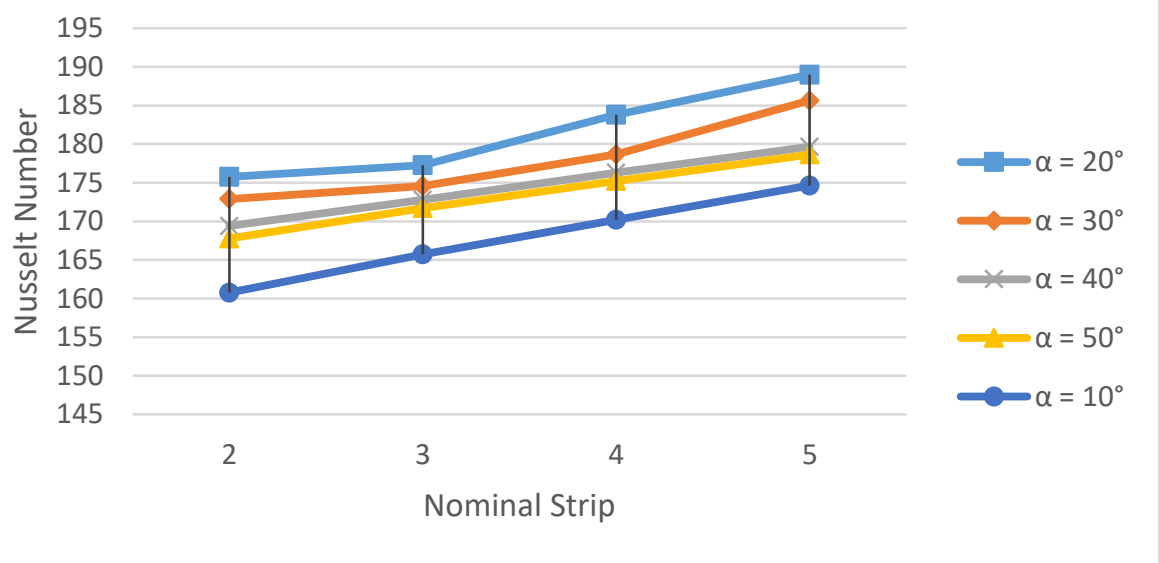

Fig. 4. Variation of the nusselt number with nominal strips for different central angles.

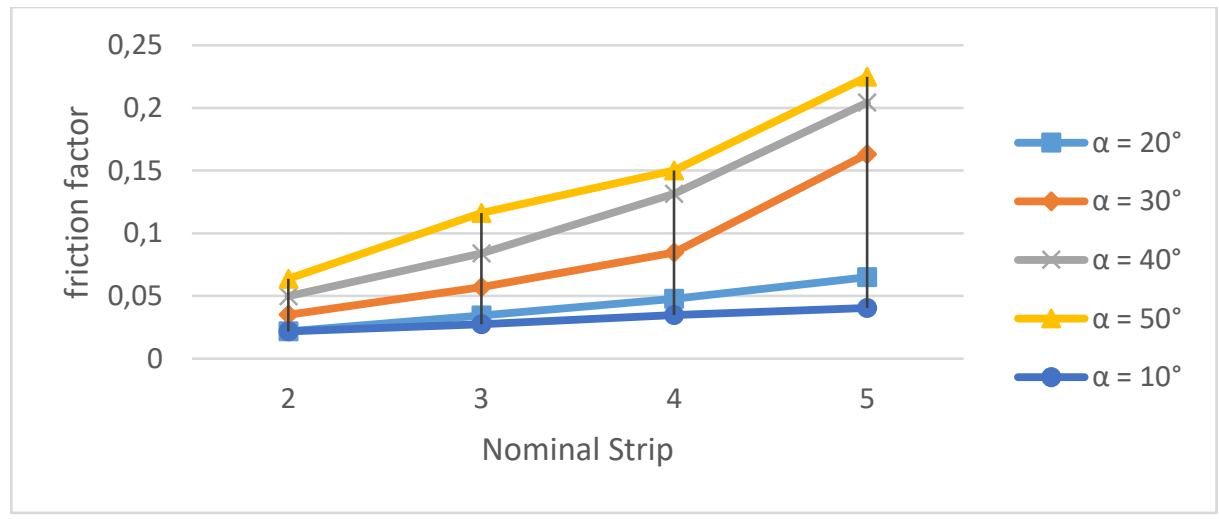

Fig. 5. Variation of the friction factor with nominal strips for different central angles. 


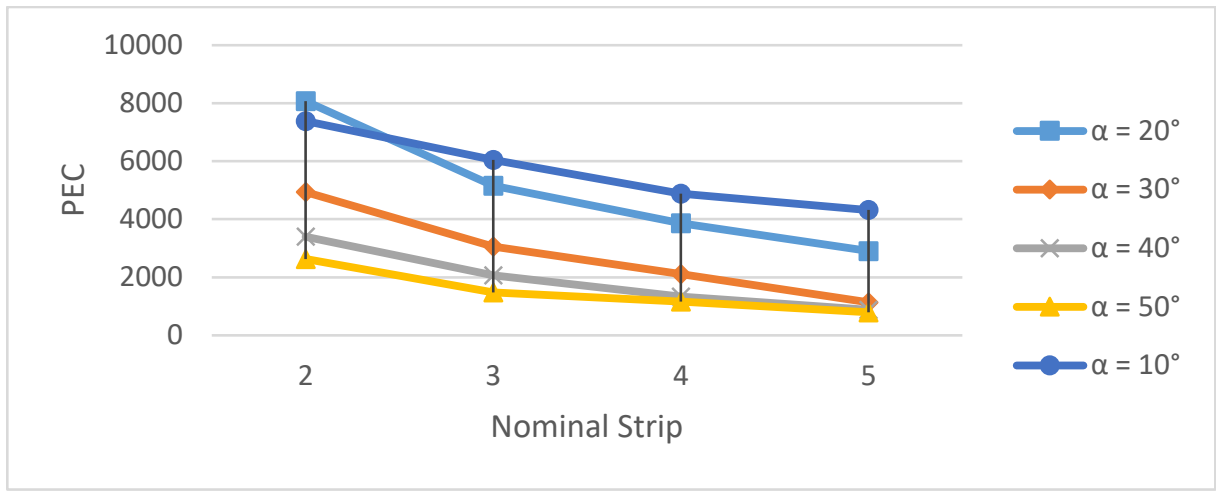

Fig. 6. Variation of the PEC with nominal strips for different central angles.

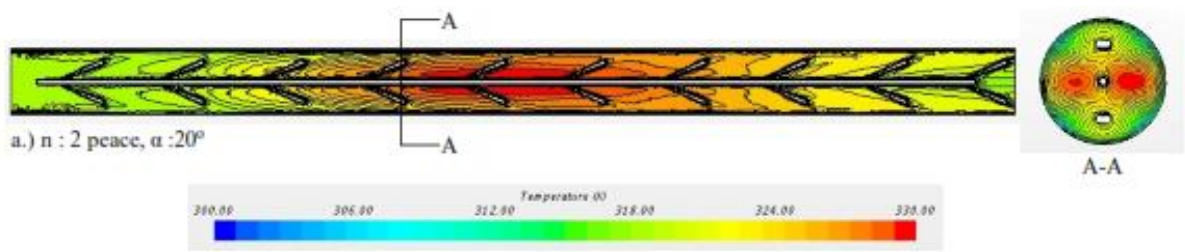

Fig. 7. Temperature contour $n=5$ and $\alpha=20^{\circ}$ at Reynolds number 18000 .

\section{Conclusions}

In this work, heat transfer and flow performence conical strips inserts was investigated by numerical simulation. It was found that multiple conical strips inserts beter than single conical strips inserts. Moreover, effects of the number conical strips inserts and central angle on heat transfer, nusselt number, and performence evaluation criterion were numerical studied. Based on the results, the main conclusions are as follows:

1. The number of conical strips inserts forms multiple vortexes in tube flow which results in a long streamline and adequate fluid mixing between the boundary and the base regions therefore enhances the heat transfer.

2. Both nusselt number and friction factor increase with increase of the number of conical strips and the central angle, but performence evaluation criteria increase with decrease of number of conical strips and decrease of central angle. The higest performence from variation is obtained at $\mathrm{n}=2$ peaces and $20^{\circ}$ of central angle at Reynolds number $>18000$.

3. Compare with previous works, the tube with multiple conical strips inserts can obatin a moderate heat trasnfer and low pressure drop, thus achieave a high overall heat transfer performence.

\section{References}

1. Bergles A E, Exp. Therm. Fluid Sci., 26, 335-44 (2002)

2. Promvonge P., Energy Convers. Manag. 49 8-15 (2008)

3. Kongkaitpaiboon V, Nanan K and Eiamsa-ard S., Int. Commun. Heat Mass Transf., 37 560-7 (2010)

4. Fan A, Deng J, Guo J and Liu W., Appl. Therm. Eng. 31, 2819-28 (2011)

5. Sripattanapipat S, Tamna S, Jayranaiwachira N and Promvonge P., Energy Procedia 100 522-5 (2016)

6. Pourramezan M and Ajam H., Appl. Therm. Eng. 105, 509-18 (2016) 